\title{
A new frontier in construction investments: Data Centres and technical factors affecting risk profile
}

\author{
Stefano Bellintani, Gianandrea Ciaramella and Alberto Celani ${ }^{*}$ \\ Architecture, Built Environment and Construction Engineering Department (ABC) Politecnico di \\ Milano, Italy
}

\begin{abstract}
The interest of Construction investors towards Data Centres is a novelty that however is not supported by an adequate level of knowledge of the technical characteristics that distinguish this particular building type. In fact, these are complex buildings, which are rarely dealt with in the literature (real estate and construction) and very different from the typical asset class of the real estate market, for which it requires a very high level of specialization. From an investor's point of view, although there are some reference standards that define some minimum quality standards, we need to widen our attention, focusing on all the technical / technological factors that influence the business model. The paper deals with this problem, trying to identify the different elements that influence the risk profile of the investment (thus omitting risk factors of another kind) and structuring them in clusters. Specifically, the paper focuses on the cost factors (passive cycle of the business model) that accompany the investment or the real estate asset "data centres" in its life cycle.
\end{abstract}

\section{Introduction}

The Construction market, especially in the consolidated and saturated markets, is turning ever-increasing attention to "alternative" real estate assets / products; the goal of investors is to seize new opportunities, identifying innovative building products, able to guarantee satisfactory returns that are consistent with the investment risk [1]. In this phase, real estate investors are showing great interest for a building type that has been little and not considered at all: the Data Centre [2]. The characteristics of the economy based on data and information in countries around the world, foreshadow concrete and broad prospects for the dissemination of these assets [3] [22]; key factors such as global urbanization, the expansion of consumer markets, household wealth and technological developments (not least, the widespread diffusion of smartphones, the growth of cloud computing, the Internet of Things and Big Data ) authorize to foreshadow the growth of a Data Center network, on a global scale, capable of governing the impressive amount of data, in continuous and accelerated growth [23] (the so-called "data explosion" phenomenon), which moves from

* Corresponding author: 'alberto.celani, stefano.bellintani, andrea.ciaramella\} @ polimi.it 
one end of the other of our planet [4]. One by-product of this increased competition for assets in particular, fund managers are now considering data centres [5]. In effect, this is a sector that allows guaranteed returns over the long term, in return for capital remuneration that presents a premium compared to traditional core sectors. An important sign also comes from the operators of the sector, the managers of the Data Centre (core business), who have introduced the possibility of opening up to collaboration with real estate investors.

\section{Scope of the work}

The Data Center is a sector that is still substantially unexplored by the Real Estate and Construction operators. So far the investments made in the world have mainly concerned the big web and digital companies, for example the "big" ones like Google, IBM or Microsoft, as well as those that offer hosting services (companies that have, as a core business, their own the management of the Data Centres and the offer of the related services). These entities are the true holders of the know-how needed to develop these super-complex buildings, symbols of the "new" world economy. If, on the one hand, for the real estate market operators seem evident the great potential for development, on the other hand it is a sector that is still very little known, which requires a highly specialized skills system (to be acquired in the shortest possible time, directly or indirectly at an organizational level) [6].

Considering also the scarce literature available on the subject (Data Center real estate), this paper intends to concentrate its attention on this cognitive gap, trying to clarify and highlight the "physical" peculiarities of these buildings. Specifically, the purpose is to define what are the technical characteristics of this particular real estate product, which intervene on investment risk.

\section{Method}

For the development of the work we proceeded, first of all, from the available scientific literature (step 1). This knowledge base offered a work platform that allowed us to learn the level of depth that can be used or implemented. The research focused on databases of University libraries that allow analyzing all the main Data Center magazines and scientific articles dealing with this topic. In order to guarantee a broad and clear vision of the problems, a cross-sectional survey was carried out that took into consideration a wide range of aspects connected to the creation and management of the Data Center. The analysis of the scientific literature was carried out following a step-by-step process that led to the identification and subsequent analysis of the only papers of interest: search by keywords, selection of papers of interest, analysis of identified papers, classification of papers. The paper selection process is derived from the analysis of articles that have been classified and evaluated according to four criteria: Main Focus - which specifies whether the contribution deals exclusively with the topic of the Data Centres or if it represents only a part (more general); Methodology - which distinguishes papers in relation to the approach used in exposure (qualitative or quantitative analysis); Themes - which goes into the details of the contributions dealt with (criticality, benefits, efficiency, innovations).

Subsequently (step 2) we proceeded to the mapping of normative / certification indications (identified thanks to the analysis conducted in the first phase) or to the relative and precise definition of the technical / technological features of the building-plant system.

The comparison between the analyzes carried out in steps 1 and 2, shared through interlocutions with the operators, allowed the synoptic identification of the elements (check lists) that contribute to defining the technical / technological features of the Data Centres; 
specifically, two basic criteria have been adopted: a) the identification of services as an expression of best practice (this has permitted the removal of territorial / national regulations and regulations); b) the identification of services able to allow an objective assessment of the quality expressed by the various technical elements.

\section{Discussion}

In the choice of location, in the design and management of complex structures such as Data Centres, it is possible to recognize some good practices that go beyond normative cogency [7].

On the other hand, it should be noted that there are regulatory standards and best practices that define the minimum requirements and performance indicators, shared at international level, that all data centres, of all types and sizes, must respect: NSI/TIA-942-A (Data Center Tiers) [8], ANSI/BICSI 002-2014, EN 50600, Uptime Institute e GR-3160 NEBS [9].

By returning the elements identified by the research to coherent evaluation sets, it was possible to organize a check list organized in 4 macro-areas: 1) location, 2) basic features, 3) surface efficiency, 4) plant engineering. The contents are shown below.

\subsection{Location}

The first factor to be evaluated is represented by environmental hazards. A Data Center, in fact, is designed and built to never interrupt its operation. Natural disasters such as floods, hurricanes, tornadoes, earthquakes, etc. they are absolutely risk factors to avoid. In general it is essential to analyze the probability and frequency of "accidental" phenomena, the proximity to electromagnetic fields, industries with hazardous processes, railways, airports and freight terminals (explosions and polluting interferences). The location is also influenced by the degree of security of the site: areas with low crime and low exposure to vandalism are always preferable.

A second very important element is the presence, or not, of sources and / or backbones of electricity supply to match the quality of the service provided. In addition to the simple data of the kWh cost, the real availability of electricity in terms of priority over other users must be evaluated, the possibility of sufficient redundancies to prevent power losses, drops, service interruptions.

A third element refers to the performance that the IT infrastructure is able to provide for the management / return of data to end users: the Band (data transmitted per second, successfully, on a link or a connection), Latency (time forward / return of a bit) and Speed (20 gig - 7/8 gig <7 gig). Furthermore, it is necessary to consider the additional investments necessary to realize the wiring that goes from the backbone (optical fibre) up to the building.

A fourth factor concerns the climate and natural resources present: natural resources available a short distance from the site (lakes, rivers, sea, geothermal) are considered lowcost sources, reusable for the HVAC system (free cooling); Dry and temperate climates are always preferable to hot and humid climates.

It is then necessary to evaluate that the presence of transport infrastructures is useful both in the construction and construction phases, and in the subsequent management phase of the building: isolated or difficult to reach locations are not very functional; in the same way those in more central areas, equipped with different but congested modes of transport, have no particular appeal. In many cases areas or buildings not included in established settlements or areas with no natural obstacles can be considered. In fact, the possibility of replicating the building or intervening, by implementing its surface, can respond to the investor provisioning needs. 
Finally, some complementary elements must be considered. First of all, the cost of energy and the quality of service in areas (presence of competitive providers), considering the possibility of using alternative production systems and / or renewable energy sources such as solar, wind energy, etc. [10].

Two other complementary elements refer to the labour force and labour costs in the reference area as well as to the typical local tax rates (taxes and incentives) [11].

\subsection{Key features}

For this particular sector it is necessary to consider some fundamental characteristics, essentially attributable to the possibility of adopting standard construction techniques and adequate plant engineering solutions in terms of performance from a purely technological and managerial point of view.

To understand the interaction of these factors and their incidence as "theoretical secondary spaces" on the spaces defined as "primary", we can refer to the technical rooms for the distribution of the systems, the distribution to the floor, the presence of false ceilings, floating floors, cavities technicians and rooms dedicated to the housing of the plants. All this inevitably falls on the structure and size of the compartments, relating to the height of the floor, the width of the building and the flexibility of the structural mesh. A Data Center can occupy the room of a building, several floors, or an entire building. It can be housed in a structure that was originally built for another use and later adapted to accommodate data centres. The type of construction can significantly influence construction and management costs, security, future expansion and operational flexibility.

Buildings similar to those for offices are not recommended, developed on several floors with reduced floor surfaces, with windowed walls. Instead, single-storey buildings, without windows, with large floor surfaces (similar to industrial structures) are preferable; these favour lower operating costs, greater possibility of safeguarding physical security and spatial flexibility.

\subsection{Surface efficiency}

Verifying the efficiency of the surfaces, extending the concept of "building efficiency" means evaluating its propensity, in structural and distributive terms, to achieve the required spatial performance.

The overall capacity of the facility is based on the size of the computer room (space used for IT and telecommunications equipment) and on the capacity of the power and cooling systems (per unit of computer room space). The balance between these 2 factors is fundamental; a lot also depends on the type of IT systems and their combination in racks.

The efficiency requirement will have to assess the presence of support areas for the activity and the organization, which can be represented as follows.

- Equipment Distribution Area" (EDA) o "White Space" (blank space); generally refers to the surface of the rack room that houses the IT equipment. Most equipment often consists of servers mounted in rack cabinets (19 "), which are inserted into lines that form corridors. This allows access to the front and back of each cabinet, considering that the servers are very different in size. Some very large Data Centres can use different containers, which can contain over 1000 servers. In general, the racks are grouped in lines of $11 / 12$ elements for 18 columns and the size of the room is multiples of 250 square meters.

- Cold corridor: it is the back of a rack line where, usually, through a raised floor and a floor grille, or a ceiling plenum, IT equipment is kept at a controlled temperature. The warm Corridor, instead, is the front part from which the staff accesses the same equipment (it has a temperature higher than the back).

- Entrance Room (ER): it is the entrance chamber to the building and accepts the 
termination of the wiring backbones (interface between data centres and technical backbone system, in external). This space, which houses the equipment of the provider (s), is in a position designed not to intercept other spaces, with a high degree of security, which can be reached by the suppliers' technicians in surveillance. There may be more input chambers to provide additional redundancy or to avoid exceeding the maximum cable lengths in large structures.

- Main Distribution Area (MDA): corresponds to the area dedicated to the distribution of structured wiring of the entire building; It houses the rack room core routers, the LAN (Local Area Network), SAN (Storage Area Network) and PBX (Private Branch Exchange) switches. It can include the horizontal distribution area when the areas destined for it are served directly from the main distribution area; the latter can also serve multiple areas of horizontal distribution, when the building is spread over several levels or in the presence of multiple rack rooms.

- Horizontal Distribution Areas (HDA): located in a coplanar position with the rack room, it is the area hosting the structured cabling system of the Data Center.

- Telecom Room: is the Telecommunications room, it hosts "the Operations Center LAN switch". It is connected to the "Operations Center" offices for remote control and to support rooms.

- Offices, Operation Center, Support Room: it is the remote control centre where all the controls of the IT room equipment are performed. In addition to the spaces dedicated to personnel, there are areas for distribution elements and technical rooms: Power (generators, UPS, diesel tank for emergency diesel generator), Cooling (production plants and chilled water storage tanks), Fire protection ( fire prevention system), Buffers, Pre-assembly room.

4.3.1. Performance indexes of the surfaces that make up the building:

- NPA (Net Productive Area) work area: this corresponds to the "White Space", the area dedicated to the rack room, the core business of the Data Center;

- Auxiliary support area: consisting of all the areas occupied by the services necessary for the use of the building (all the spaces listed below, with the exception of the rack room, the ratio between these two parameters can vary from $1 / 2$ to $1 / 3$ );

- Gross internal area GIA (Gross Internal Area): includes the surface of all floors, excluding perimeter walls (Productive Efficiency Indicator: percentage ratio between the production area and the gross internal surface of the entire building).

\subsection{Building Technology}

4.4.1. Control and energy consumption: PUE (Power Usage Effectiveness), the ratio of total power absorbed by the Data Center (PT) and that used by the only IT equipment (PIT). It is an index that allows to evaluate the energy consumption of functions not related to computer systems (cooling, distribution redundancies, security and safety), allowing to evaluate how efficient a computing centre is and how much electric power is dedicated to the power supply of the equipment IT compared to ancillary services (UPS conditioning or leaks) [12].

4.4.2. Communication / wiring system; fundamental is the presence of a structured cabling that allows high performance in data exchange. In addition, the fibre backbones that connect to the Data Center must be in a ring structure, or otherwise come from two different points of a star network; secondly, they must guarantee priority in the event of a failure to resolve interruptions in the supply.

4.4.3. Electrical system; first of all, the supply must be supported by a "standby" system made up of one plus fuelled power generators and UPS groups. The generator motor must be activated both manually and automatically, for voltage drops equal to or greater than $15 \%$, and guarantee operation from 4 hours to 60 days.

The internal wiring system is designed to be sectioned and duplicated in its entirety, 
ensuring that maintenance operations do not require the entire system to be shut down; also the standby elements - UPS and emergency generators must reach the IT equipment with a double connection). Finally, it is advisable to provide an adequate grounding system and an effective lightning protection system.

4.4.4. Air conditioning system (HVAC): the system must guarantee temperature and humidity control, according to the "ASHRAE guidelines" (range of $18-27^{\circ} \mathrm{C} / 64-81^{\circ} \mathrm{F}$, dew point range of $5-15^{\circ} \mathrm{C}-41-59^{\circ} \mathrm{F}$, relative humidity $60 \%$ for Data Center environments, etc.), the energy savings and the micro-climatic performances required The HVAC ducts near the underside of the racks increasingly appreciated and performing solution.

4.4.5. Fire-fighting system: these are fire protection systems consisting of active and passive elements. Passive protection elements include fire walls and REI doors. The active system consists of high sensitivity smoke detectors (for power interruption and fire suppression), smoke suction lines, gaseous or mixed systems.

4.4.6. Anti-intrusion system and security: CCTV systems, control-lights and permanent security guards are essential elements; especially if the centre is of considerable size or contains sensitive information. Control-access systems must allow the recognition of authorized persons, registration and verification of transits, different degrees of access (external operators and employees referred to different levels of protection); in fact the routes and the connections of the building must be designed to allow the passage according to specific security procedures / priorities.

4.4.7. BMS (Building Management System) or DCIM (Data Center Infrastructure Management) systems: their presence is fundamental as it guarantees the management of information and automation in a centralized and integrated way. The management of the Data Center infrastructure (DCIM) represents the need for integration of IT technologies and the disciplines / models typical of facility management. Depending on the type of application, DCIM products can help Data Center managers identify and eliminate sources of risk to increase the availability of critical IT systems or identify interdependencies between IT infrastructure and infrastructure and critical issues in system redundancy [13].

\section{Conclusions}

The amount of data and information processed every day grows exponentially; the research firm IDC (International Data Corporation), the first international level specialized in research in the ICT and digital innovation sectors, believes that in 2020, 35 zettabytes of data will be generated in the world; equal to 35 times the amount of data generated in 2010. The ability to use this data appropriately constitutes a competitive advantage for those companies and organizations that base their activity on the ability to process information in a "smart" way (the last frontier is Big Data). On the other hand, it is now clear that data are and will increasingly be the basis of new products and services and, more generally, of the world economy. All of this leads to an exponential growth of data centres globally for the next few years.

Until now, the scientific literature has mainly investigated the data centre's IT structure and the set of methods and technologies that make information transmission, reception and processing systems, leaving the evaluation of the "container" more indeterminate. In fact, if we carefully observe the relevant regulations, these include, in a broader and holistic vision, all the building and plant components of the calculation centres, defining minimum quality standards, in relation to the types of IT services provided. It follows that there is a direct relationship between the IT services and those of the buildings that guarantee their functionality.

The research has paid particular attention to the characteristics of the building as a 
"container", analyzing its ability to respond, as well as regulatory and energy-performance aspects, to a series of requirements that can determine an overall performance index and that must necessarily to be evaluated in consideration of the overall useful life cycle (for this reason the design and management phase cannot be seen in complete synergy). Naturally, these requirements are closely related to the real estate investment or the value of the property, given that a performance-driven and evolved data centres is, in general terms, more attractive and less expensive over time (passive investment cycle).

It should be noted that, according to some specialized investors, today data centres are seen as an investment alternative compared to other more traditional real estate products. The scenario that can be prefigured, based on the initiatives currently under study and implementation, consists of a change of course towards structures different to those currently existing for density and plurality of conductors / end users (who could share the same structure: co-location).

The economic value of a data centres consists, first of all, of its plant-technological component, that is, IT installations that fully represent the core business of the function established in the building and the largely predominant part of the initial investment. In this sense, the identification of the technical elements that contribute to defining the quality of a data centre coincides, in fact, with the definition of the quality of the real estate transaction or with the identification of the related risk factors [14].

Assuming the point of view of the property and focusing the attention on the passive cycle of the investment or (above all) on the costs of construction, management, refurbishment and therefore on the risk profile dependent on the technical-technological components of the building, the model realized by the conduct research, could be very useful for investors. The elements identified, appropriately organized (check list) and weighted by importance / impact on the business model (investment), could flow into a tool that would allow a timely evaluation (rating) to be extracted from the "immobile risk" component of the investment [15]. Naturally, considering the high degree of obsolescence of the building-plant system, it should be a tool subject to periodic updates. All this would allow investors, who usually draw on a different system of expertise, to create / obtain a series of precise indications, realizing an overview of the technical / technological profile of the asset on which they intend to invest.

\section{Results}

The risk profile of investments in the data centre is based on specific risks concerning the elements identified in the 4 reference areas (location, fundamental characteristics, surface efficiency, plant engineering) and which, of course, are closely related to the business model [16].

By reasoning across the board, risks can be summarized as follows:

- initial high capital investment;

- need for specialized management;

- risk of technological obsolescence;

- uncertainty about the cost of energy

First of all, it should be noted that a standardized evolved data centre (Tier 3) has a realization cost of $€ 5,000$ / sq.m (gross area); an office building with 6 floors above ground is not much higher than $€ 1,000$ / sqm [17]. For this reason it is always a good practice to provide a modular construction that makes any expansions over time easier; in this way the space can be created only if and when necessary. It must also be considered that rapid technological development involves frequent changes in both the layout and use of the data centres and the installed infrastructures; a data centre may be obsolete after only 8-10 years. The choice of a modular development, in short, also concerns the flexible design of the 
plants and their spaces (for example: independent HVAC units, sectioned on the single module) [18].

Another fundamental aspect (risk for investors) concerns the management phase. Inevitably, given the high complexity and preponderance of the technological assets present, highly specialized personnel are required; and this entails higher operating costs than any other asset class. The operating cost for a data centre stands on average around $€$ 60-65.00 / sqm (data room), compared to only € 5.00-6.00 / sqm related to a medium-level office space [19]. Furthermore, it must be considered that: 1) most of these operating costs are variable because, over time, the tenant may need to rent additional racks; 2) regardless of the size of the data centre, it is always necessary a dedicated, at least security guard.

A further risk refers to the high degree of obsolescence of IT equipment which entails high maintenance and replacement costs. Therefore it is necessary to foresee and monitor them in a precise way, in the relative life cycle. The maintenance cost, on average, is 200.00-230.00 / sqm (data room), compared to $€ 7.00-8.00$ / sqm related to a medium-level office [20].

Lastly, it should be noted that, given that data centres are highly energy-consuming buildings, the uncertainty about future energy prices also affects the increase in investment risk. However, this can be mitigated by invoicing the energy directly to the customer and by contractually providing "energy premiums" for the most efficient managers (management fees).

In addition to these elements, it should be considered that, in traditional real estate investments, the investment considers both the income and the residual value (estimated by capitalizing the sale of the property at the end of the investment period), making them, in some way, linked to the possibilities of capital gains connected to the resale values. In the case of data centres, practice considers a residual zero value at the end of the investment period considered. This means that the investment must produce an income equivalent to capital expenditure in the 10-15 years of activity. Data centres, in particular, are subject to amortization rules, which means that the building will have to be depreciated at a certain rate. Given that the value of a data centres is primarily made up of installations (up to $80 \%$ ), most of the investment is amortized over 10 years; the construction of the structure (building), however, in 30 years [21].

Although there are no data on the volatility of the data centres market at this time, it is expected that the market will be less volatile than other sectors of the real estate sector. In fact, the data centres market has weaker links with the business cycle. If we analyze the relationship between the performance of the economy and the tertiary and industrial real estate market, it is possible to notice a direct relationship; the data centre market, on the other hand, does not show direct links with the economic cycle, moving according to different logics and above all being linked to a type of technologies / services that grow independently of the macroeconomic context of reference.

\section{References}

1. L. Gareth, Emerging Trends in Real Estate The global outlook, PWC \& ULI, London (2018)

2. Jones Lang Lasalle, Data Center Outlook, JLL IP, London (2018)

3. CBRE, European Industrial \& Logistics MarketView (Q2), London (2014)

4. M. T. Lucarelli, E. Mussinelli, L. Daglio, Resilient Design, Maggioli, Milan (2018)

5. J. Dodsworth, Data centers: the alternative investments class, White \& Case, London (2018)

6. S. Amparbeng, Data center REITs: bringing innovation to property investments, John Carpenter House, London (2018) 
7. D. Centofanti, The standards for design, implementing and certifying a data center,

8. T. Daim, J. Justice, M. Krampits, M. Letts, G. Subramanian, M. Thirumalai, Data center metrics An energy efficiency model for information technologu managers, Management of Environmental Quality, 20 (2009).

9. K. Kant, "Data Center Evolution A tutorial on state of the art issues and challenges", Computer Networks, 53, (2009)

10. K. G. Brill, Data center energy efficiency and productivity, White paper, The Uptime Institute, Santa Fe (2016)

11. B. Cartwright, Property Taxes: The New Challenge for Data Centers Vizualiz Inc., New York (2013)

12. ASHRAE Technical Committee 9.9, Mission Critical Facilities, Technology Spaces and Electronic Equipment. Thermal Guidelines for Data Processing Environments American Society of Heating, Refrigerating and Air-Conditioning Engineers (2012)

13. W. Torell, "Data Center Physical Infrastructure: Optimizing business value", APC by Schneider Electric (2008)

14. S. Bennion, L. Laird, Master Thesis Massachusetts Institute of Technology, Program in Real Estate Development in conjunction with the Center for Real Estate, pp- 66-69, MIT Libraries (2016).

15. L. Dave, Data Center Journal, 40, pp. 75, (2015)

16. P. McAllister, P. Loizou, The appraisal of data centres: deconstructing the cash flow, Journal of Property Investment \& Finance, 27, pp.65-80, Emerald (2009)

17. T. Lerman, Data center real estate trends to watch for, T5 Data Center, Bisnow (2018)

18. T. R. Louwerens, Data Centre Investments: Investment model \& associated risk-return profile, Master Thesis Delft University of Technology (2014)

19. European Commission H2020, Data centre energy efficiency guidelines, extensive online training material, case studies/lectures, EURECA Data Centre Project, University of East London, Docklands Campus, University Way, London, E16 2RD (2018)

20. Jones Lang Lasalle, Data Center Barometer, JLL IP, London (2012)

21. Jones Lang Lasalle, Global Market Perspective, JLL IP, London (2013)

22. M. Diduch, Late in the Real Estate Cycle: Data Centers continue to outperform, National Real Estate Investor Journal, NREI Daily (2018)

23. V. G. Borkovskaya, E. Degaev, I. Burkova: Environmental economic model of risk management and costs in the framework of the quality management system. MATEC Web of Conference 2018, International Scientific Conference Environmental Science for Construction Industry - ESCI 2018.Volume 193 (2018). Ho Chi Minh City, Vietnam, March 2-5, 2018

24. V.G. Borkovskaya: Complex models of active control systems at the modern developing enterprises. Advanced Materials Research (Volumes 945-949). Chapter 22: Manufacturing Management and Engineering Management. June 2014. Pages 30123015. DOI: $10.4028 / w w w . s c i e n t i f i c . n e t / A M R .945-949.3012$ 